\title{
Avaliação da arborização urbana da Cidade de Manaus por seus residentes
}

\author{
Evaluation of urban afforestation of Manaus City by her residents \\ ${ }^{1}$ Nelson Felipe de Albuquerque Lins Neto; ${ }^{2}$ Paulo Roberto Pires de Sousa; ${ }^{3}$ Álefe \\ Lopes Viana; ${ }^{4}$ Maikel Lamego Guimarães Mari; ${ }^{5}$ Suzana Helen da Silva Medeiros \\ 1 M.Sc. Agronomia Tropical, Universidade Federal do Amazonas - UFAM, Manaus, AM, Brasil \\ 2 M.Sc. Economia, Faculdade Salesiana Dom Bosco - FSDB, Manaus, AM, Brasil \\ ${ }^{3}$ M.Sc. Ciências Florestais e Ambientais, Universidade Federal do o Amazonas - UFAM, Manaus, AM, Brasil \\ ${ }^{4}$ M.Sc. Botânica, Instituto Nacional de Pesquisas da Amazônia - INPA, Manaus, AM, Brasil \\ ${ }^{5}$ Acadêmica de Engenharia Florestal, Universidade Federal do Amazonas - UFAM, Manaus, AM, Brasil
}

\begin{abstract}
Resumo
O objetivo deste estudo foi quantificar e avaliar a percepção sobre a arborização na cidade de Manaus por seus residentes e relaciona-la aos investimentos realizados pelo governo municipal. Os dados foram obtidos através de questionários online que foram distribuídos entre usuários de redes sociais através da internet e smartphones. Os resultados indicaram que apenas 3\% dos participantes consideraram muito boa a arborização na cidade de Manaus e $42 \%$ muito ruim, sendo as zonas norte e leste com 48 e $61 \%$, respectivamente, as piores da cidade. Quanto aos benefícios da arborização, $72 \%$ apontaram o conforto térmico como sendo o mais importante. A maior preocupação foi com o risco de tombamento das árvores, seguido pela interferência na rede elétrica, com 25 e 24\%, respectivamente. As espécies mais desejadas para a arborização da cidade foram o pau pretinho, ipê e frutíferas em geral. Dos entrevistados, apenas $65 \%$ estariam dispostos a contribuir com algum valor para a arborização, mesmo com $71 \%$ destes considerando os investimentos públicos insuficientes para ampliação e manutenção dos espaços verdes. Quando comparados com cidades como São Paulo e Campo Grande, os itens sobre investimento como percentual do PIB municipal para a arborização, $\mathrm{R} \$ / \mathrm{km} 2$ e $\mathrm{R} \$ /$ habitante, foram sistematicamente inferiores.
\end{abstract}

Palavras-chave: Espaços verdes; investimentos públicos; gestão e percepção ambiental.

\begin{abstract}
The aim of this study was to quantify the perception of afforestation in the city of Manaus by their residents and it relates to investments made by the municipal government. Data were obtained from 647 online electronic questionnaires distributed among users of social networks on the internet and smartphones. The results indicated that only 3\% of participants considered very good afforestation in Manaus and $42 \%$ very poor, and the north and east areas with $48 \%$ to $61 \%$ the worst of the city. As for the benefits of afforestation, $72 \%$ indicated thermal comfort as the most important. The biggest concern was the risk of tipping, followed by interference power grid, with 25 and $24 \%$, respectively. The most remembered species were pau pretinho, ipê and fruit trees. Of the respondents, only $65 \%$ would be willing to contribute whit some value for afforestation, even with $71 \%$ of those considering the insufficient public investments for expansion and maintenance of green spaces. When compared to cities like São Paulo and Campo Grande items as a percentage of GDP invested in municipal afforestation, $R \$ / \mathrm{km} 2$ and $R \$ /$ capita, were always lower.
\end{abstract}

Keywords: Green spaces; Public investment; environmental management and perception. 


\section{Introdução}

Aproximadamente há 10.000 anos, o homem começou a cultivar as plantas e criar animais, que ele mesmo domesticou introduziu e multiplicou, em diversos ambientes, transformando, assim, os ecossistemas naturais originais em ecossistemas cultivados, artificializados e explorados por seus cuidados. Dessa forma, a agricultura tornou-se o principal fator de transformação do ambiente, e seus ganhos de produção e de produtividade, através de técnicas, ferramentas e equipamentos criados e aperfeiçoados por homens que não produziam seu próprio alimento, permitiu o desenvolvimento de diferentes categorias sociais, aumentando a concentração de pessoas em aldeias, que posteriormente se tornaram vilas culminando com o surgimento das primeiras cidades (MAZOYER e ROUDART, 2010).

Nas cidades, a humanidade encontrou um local melhor para viver, desenvolver e enriquecer, no entanto, houve um distanciamento de seu ambiente natural promovido pelas edificações e a urbanização do ambiente das cidades (TORRES, 2009).

Por causa deste distanciamento, acredita-se que a arborização das cidades, provavelmente, surgiu com o intuito de garantir o vínculo ancestral do homem com a vegetação que era mais abundante antigamente (MALAVASI e MALAVASI, 2001) ou ainda, simplesmente pelos benefícios da arborização como a redução de ruídos, as modificações do microclima, a alteração do campo visual, a melhoria do hábitat da fauna silvestre, assim como a recreação e lazer urbanos (CEMIG, 2011).

Dessa forma, observa-se que o bem estar do homem que habita a cidade, esta ligado ao componente vegetal urbano e que o plantio de árvores nas cidades significa atender necessidades humanas. No entanto, a percepção da arborização urbana pela população tem sido posta em um segundo plano pelos administradores e técnicos que a praticam (MALAVASI e MALAVASI, 2001).

Segundo o IBGE (2010), dentre as capitais brasileiras, a cidade de Manaus, com 25,1\% de arborização urbana de seus espaços públicos, aparece como a antepenúltima colocada, a frente apenas de Belém (22,4\%) e Rio Branco (13,9\%). Muito longe da primeira colocada Campo Grande, que apresenta $96,4 \%$ de seus espaços públicos em área urbana arborizados, sendo esta a capital brasileira mais arborizada.

Outro título nada agradável para a cidade de Manaus é a de penúltima colocada no índice de bemestar urbano dentre as metrópoles brasileiras, ficando apenas afrente de Belém. Este índice considera, entre diversos itens usados como indicadores, condições ambientais (RIBEIRO e RIBEIRO, 2013).

A arborização urbana pode ser considerada um destes componentes e para sua avaliação, geralmente são utilizados aspectos biológicos como a observação e a mensuração de variáveis, com tudo, já se admite que outros fatores como a influência psicológica e estética, sejam importantes (OLIVEIRA, 1996).

Algumas pesquisas subjetivas mostraram que a arborização influenciava até mesmo a escolha de um individuo quanto ao novo lugar para viver, dando preferencia aos locais com maior componente arbóreo (MASCARÓ, 2012).

Essa percepção ambiental é definida por Villar (2008) como as formas que os indivíduos vêem, compreendem e se comunicam com o ambiente, considerando-se as influências ideológicas de cada sociedade e que as respostas ou manifestações daí decorrentes são resultados das percepções, individuais e coletivas, dos processos cognitivos, julgamentos e expectativas de cada pessoa.

Assim, a percepção, por definição, é o ato, efeito ou faculdade de perceber, adquirir conhecimento a partir de algo por meio dos sentidos como visão, audição e tato. Dessa forma, observa-se a percepção como um processo cognitivo-cultural que envolve mecanismos de percepção externa e a elaboração mental, que seria uma reflexão sobre as sensações adquiridas do meio (AMANTE, 2001 apud COSTA et al., 2012). 
Existem diversas formas de estudar a percepção ambiental das pessoas, entre elas, podem ser utilizados questionários, mapas mentais ou contorno, representação fotográfica, entre outras, além de trabalhos em percepção ambiental que buscam também promover a sensibilização, bem como o desenvolvimento do sistema de percepção e compreensão do ambiente (ROPPA et al., 2007).

Desta forma, os estudos que se caracterizam pela aplicação da percepção ambiental objetivam investigar a maneira como o homem enxerga, interpreta, convive e se adapta à realidade do meio em que vive (OKAMOTO, 1996).

Milano (1984) alertou que a falta de participação comunitária nos programas de arborização pode gerar sérios prejuízos. Como o "vandalismo" evidenciando, assim, a necessidade de se fazer planejamentos mais abrangentes para a arborização em uma cidade, considerando uma avaliação das percepções dos seus usuários finais.

Segundo Lüdke e André (1986), para realizar uma pesquisa é preciso promover um confronto entre os dados, as evidências, as informações coletadas sobre determinado assunto e o conhecimento teórico acumulado a respeito dele. Trata-se de construir uma porção do saber.

Para a coleta desses dados, é muito comum à utilização de questionários contendo questões feitas para gerar as informações necessárias para se atingir os objetivos de um projeto e que é especialmente utilizado pelas ciências sociais sendo, então, importante para a mesma (PARASURAMAN, 1991).

Atualmente as principais atividades econômicas, sociais, políticas e culturais estão estruturadas através da Internet (CASTELLS, 2004) que, vem sendo utilizada como um meio de comunicação em expansão, podendo oferecer diversas oportunidades para a realização de pesquisas (VIEIRA et al., 2010) que estão ficando cada vez mais populares entre os pesquisadores (MALHOTRA, 2006).

Segundo Castells (2004), a comunicação é à base da atividade humana, e a Internet está mudando o modo como nos comunicamos, dado que ela é o primeiro meio que permite a comunicação de muitos para muitos a uma escala global e no tempo escolhido pelas pessoas.

Shneiderman (1998) afirma que muitas pessoas preferem responder a um questionário apresentado na tela do computador do que impresso, o que tornaria o planejamento, a elaboração e a aplicação de questionário online, através da rede mundial de computadores, uma ferramenta poderosa para a obtenção de respostas dos usuários.

Observa-se também que, além do baixo custo e da rapidez, a pesquisa via Web teria outras vantagens como a desinibição das pessoas em frente ao computador, tendendo a serem mais verdadeiras. A receptividade aumenta pelo fato do entrevistado responder às perguntas no local e no momento de sua preferência (SOUZA, 2000).

O objetivo deste trabalho foi quantificar a percepção da arborização urbana da cidade de Manaus por seus residentes e a participação popular quanto a criação de politicas bem como investimentos públicos em arborização na cidade.

\section{Material e métodos}

O estudo foi realizado através da Rede Mundial de Computadores (internet), onde os dados foram coletados a partir de formulários online distribuídos por meio de link em redes sociais e aplicativos de smartphone de mesma natureza, o qual remetia aos usuários um questionário semiestruturado para ser respondido.

O questionário foi composto por 14 questões fechadas e uma aberta (tabela 1) sobre o estado atual da arborização na cidade de Manaus, conforme suas percepções, num contexto geral e localizado, sendo este referente à cidade como um todo e às áreas da cidade em que os participantes habitavam, respectivamente.

Para uma amostragem ampla e heterogênea, os questionários foram repassados entre os próprios usuários das redes sociais e aplicativos de smartphones aos seus contatos, ampliando, assim, a base de dados, aqui chamado de "piramidização", pois, essa metodologia, consiste basicamente do mesmo princípio, estendendo-se de um ponto inicial singular até uma base final ampla. 
Tabela 1. Questões abordadas no questionário.

\begin{tabular}{cc}
\hline $\begin{array}{l}\text { QUESTÃO } \\
\left(\mathbf{N}^{\mathbf{0}} \mathbf{)}\right.\end{array}$ & PERGUNTAS \\
\hline 1 & Idade \\
2 & Sexo \\
3 & Grau de instrução \\
4 & Renda familiar \\
5 & Qualidade da arborização na zona em que habita \\
6 & Qualidade da arborização na cidade como um todo \\
7 & Aspectos mais relevantes da arborização \\
8 & Contribuição e grau de importância da arborização \\
9 & Aplicação dos recursos \\
10 & Espécies desejadas \\
11 & Desvantagens \\
12 & Eficácia dos investimentos públicos na arborização \\
13 & Valor aplicado pelo município em arborização \\
14 & Conhecimento ou participação no plano diretor de arborização e participação em \\
15 & pesquisas da mesma natureza \\
\hline
\end{tabular}

Após a coleta de dados, os mesmos foram transformados em valores percentuais para simplificar a visualização das informações geradas.

Posteriormente, foram convertidos em planilhas eletrônicas, onde foram submetidos à análises para posteriormente gerar as informações "alvo" deste trabalho.

\section{Resultados e Discussão}

Ao todo foram respondidos 647 questionários, no período de 15 de janeiro a 20 de fevereiro de 2014, onde foi possível observar que as idades dos participantes foram predominantes entre 19 e 30 anos, seguida das idades entre 31 a 45 anos, 46 a 65 e até 18 anos de idade (Figura 1A). Para idades acima de 65 anos não houveram registros, indicando que o ambiente virtual ainda é majoritariamente frequentado por jovens e adultos.

Com relação ao nível de escolaridade, não houveram registros de participantes com apenas o ensino fundamental incompleto ou completo. No entanto, a participação em massa de universitários, graduados e pós-graduados ficou evidente, enquanto os que afirmaram ter o ensino médio incompleto e completo foram de apenas 1 e 3\%, respectivamente (Figura 1B).

Quanto à renda mensal dos participantes, foram subdivididos pela Definição das Classes Econômicas (DCE) conforme Nery (2012), sendo a classe "E", com renda familiar mensal até dois salários mínimos ( $\mathrm{R} \$ 1.358,00)$, teve participação de $21 \%$ na pesquisa, enquanto as classes " $\mathrm{D}$ " (entre 2 e 3 salários), " $\mathrm{C}$ " (entre 3 e 10 salários), " $\mathrm{B}$ " (entre 10 e 20 salários) e "A" (acima de 20 salários) foram de $22 \%, 44 \%, 7 \%$ e $7 \%$, respectivamente (Figura 1C). Assim, a participação de usuários com a renda familiar superior a $\mathrm{R} \$ 1.356,00$ foi de $79 \%$ do total. Além disso, ficou evidente que o número de mulheres é ligeiramente menor de que o de homens (Figura 1 D). Todos estes resultados foram coerentes aos encontrados por IBGE (2006), indicando que, no uso da internet é predominante a presença de homens entre 19 e 30 anos, com alto grau de instrução, e renda superior a três salários. 


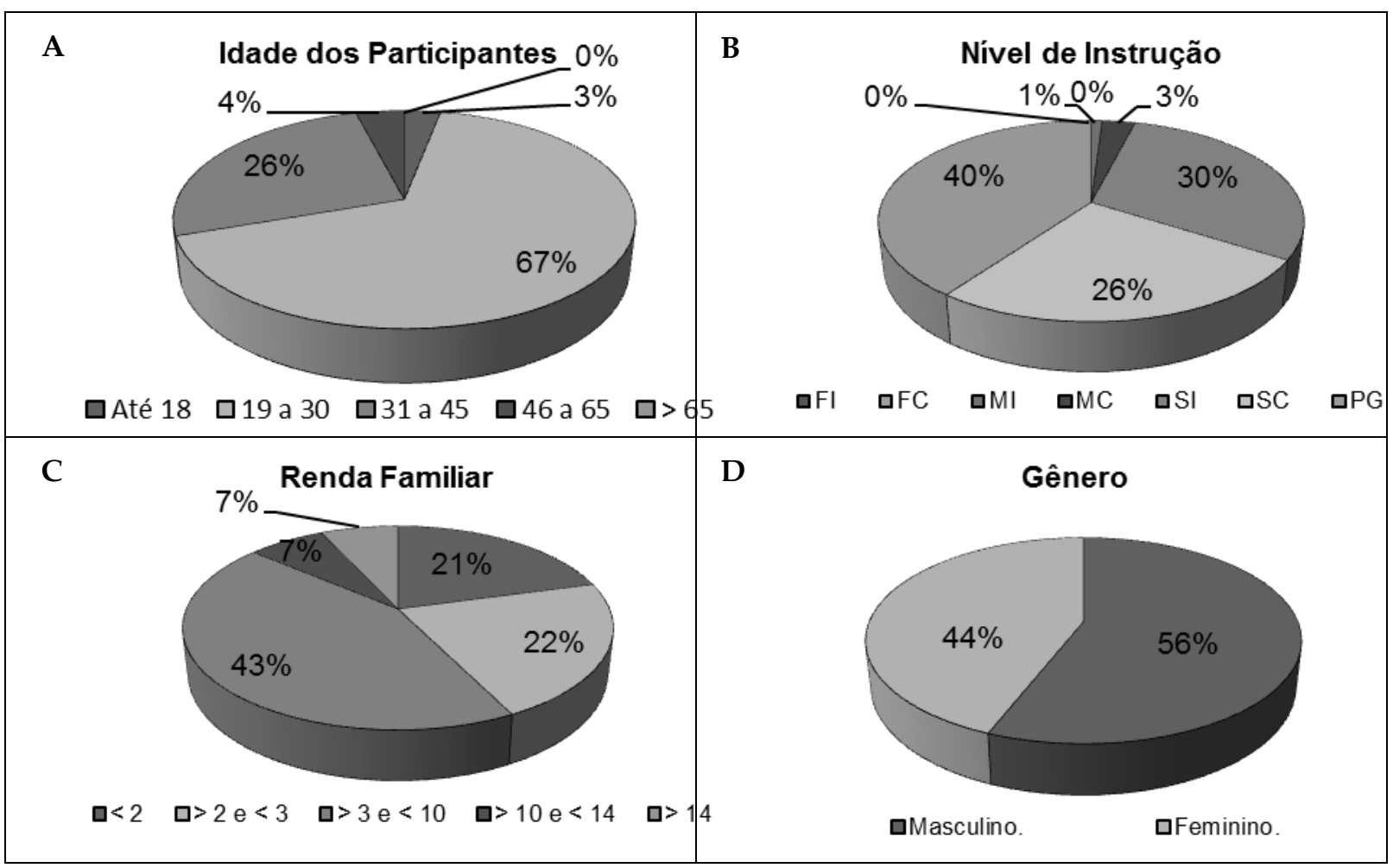

Figura 1 - Participação por idade (A), nível de instrução dos participantes (B) onde: FI: fundamental Incompleto; FC: Fundamental completo; MI: Médio Incompleto; MC: Médio Completo; SI: Superior Incompleto; SC: Superior Completo e PG: Pós-Graduado. Renda familiar em função do salário mínimo (C) e gênero dos participantes da pesquisa (D) Fonte:

Quando questionados sobre as zonas da cidade em que habitavam, $47 \%$ dos entrevistados disseram morar nas zonas sul e centro-sul, conhecidas por abrigar, predominantemente, famílias entre as classes A, B e C.

Em seguida, aparecem as zonas oeste e centro-oeste com $23 \%$ de participação e por ultimo as zonas leste e norte, que são regiões periféricas, conhecidas pela predominância entre famílias de classes C, D e E, com 18 e 12\%, respectivamente (Figura 2). Estes resultados corroboram com os valores apresentados na Figura 1C, que caracteriza a renda familiar dos participantes.

\section{Participação por Zona}

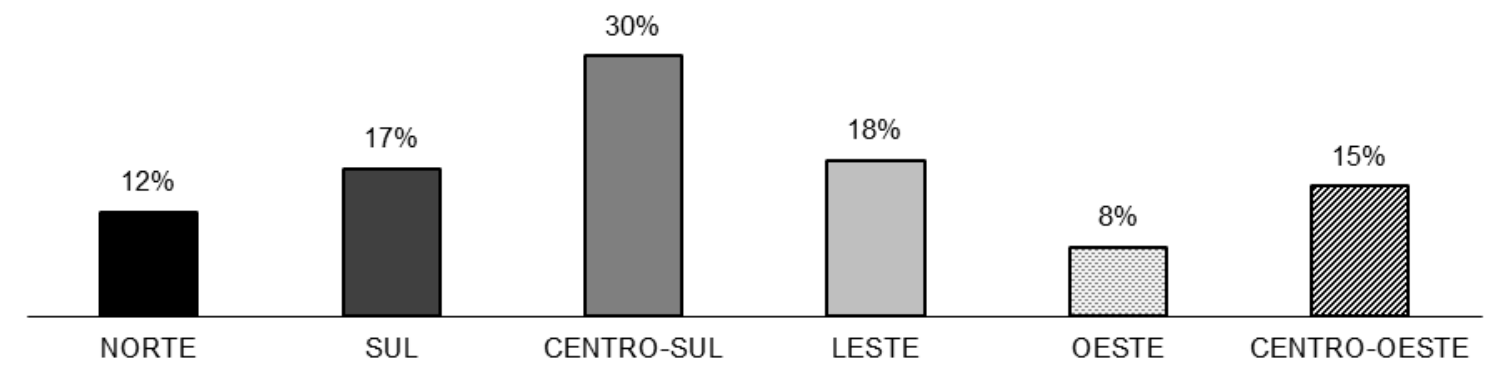

Figura 2 - Distribuição dos participantes da pesquisa em função da zona da cidade em que habitam

Com relação à percepção da arborização nas zonas em que habitam, as zonas leste e norte obtiveram as piores avaliações, sendo consideradas muito ruins por 61 e $48 \%$, respectivamente, de seus residentes. Já as melhores avaliações foram feitas pelos munícipes que residem nas zonas 
oeste/centro-oeste e sul/centro-sul, que foram avaliadas como bom ou muito bom por 17 e $14 \%$, respectivamente (Tabela 2 ).

Apesar da zona norte da cidade ter sido uma das regiões pior avaliadas, também teve avaliação entre boa ou muito boa por $15 \%$ de seus moradores. Valor esse, superior, inclusive, ao registrado nas zonas sul/centro-sul.

Este comportamento contraditório entre as piores e melhores avaliações podem estar relacionados à forma como pode ter sido feita a arborização nesta zona da cidade. Se esta foi realizada de forma irregular, sem seguir planos ou critérios para que fossem plantadas as árvores, é possível que, dentro de uma mesma zona, existam pontos com maior incidência do componente arbóreo enquanto em outros possam ser sensivelmente menores ou até inexistentes, influenciando, assim, as respostas deste grupo de entrevistados.

Quando questionados sobre a arborização na cidade de Manaus como um todo, $74 \%$ dos entrevistados consideram ruim ou muito ruim a ocupação de espaços verdes em logradouros públicos e apenas $6 \%$ afirmaram estar satisfeitos ou muito satisfeito.

Tabela 2. Percepção da arborização urbana em percentual pelos participantes da pesquisa com relação à zona em que habita e a cidade de Manaus como um todo

\begin{tabular}{cccccc}
\hline & \multicolumn{5}{c}{ QUALIDADE DA ÁRBORIZAÇÃO (\%) } \\
\cline { 2 - 6 } ZONA & Muito Bom & Bom & Regular & Ruim & Muito Ruim \\
\hline Norte & 5 & 10 & 28 & 10 & 47 \\
Sul/Centro-Sul & 1 & 13 & 29 & 25 & 32 \\
Leste & 0 & 3 & 9 & 27 & 61 \\
Oeste/Centro-Oeste & 7 & 10 & 33 & 31 & 19 \\
Manaus & 3 & 3 & 20 & 32 & 42 \\
\hline Média (\%) & 3,2 & 7,8 & 23,8 & 25 & 40,2 \\
\hline
\end{tabular}

Apesar dos esforços do atual governo municipal em realizar a arborização em vários pontos da cidade, principalmente em vias com grande fluxo de veículos e pedestres (figura 3), os resultados obtidos nesta pesquisa, sugerem que a população ainda não notou ou percebeu os investimentos aplicados nesses itens, uma vez que os resultados da arborização podem levar alguns anos para serem percebidos.

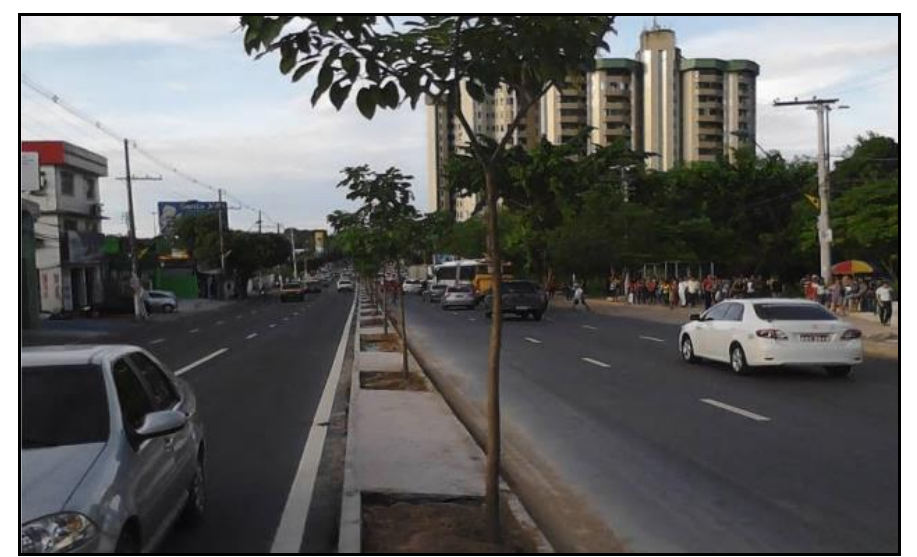

Figura 3. Árvores recém-plantadas na Av. Djalma Batista. Uma das principais vias da cidade de Manaus

Quanto aos benefícios que a arborização urbana pode proporcionar, foram apontados como os mais importantes o conforto térmico, com $72 \%$ e a fixação de gases do efeito estufa como o $\mathrm{CO}_{2}$, presente na atmosfera, com $20 \%$. Já os outros itens como paisagismo e drenagem, tiveram apenas 7 e $1 \%$, respectivamente (Figura 4A). Para o item conforto acústico, não houve registros, indicando que os manauenses não percebem os efeitos da arborização na redução dos ruídos. 
Os benefícios mais citados pelos participantes, como o conforto térmico, foram obtidos através do sombreamento produzido pelas árvores e pela evapotranspiração. Em uma cidade como Manaus, onde sensação térmica pode ultrapassar os $40^{\circ} \mathrm{C}$, faz sentido que seja o beneficio mais citado.

Apesar de $72 \%$ das pessoas julgarem importante a questão microclimática urbana, apenas $65 \%$ dos participantes afirmaram que contribuiriam, através de um eventual tributo especifico, para auxiliar no financiamento das atividades diretamente ligadas ao plantio de árvores e a manutenção dos espaços verdes da cidade. $O$ tributo sugerido na pesquisa teria seus valores variando entre $R \$ 1,00$ e $R \$ 50,00$ por ano (Figura 4B).

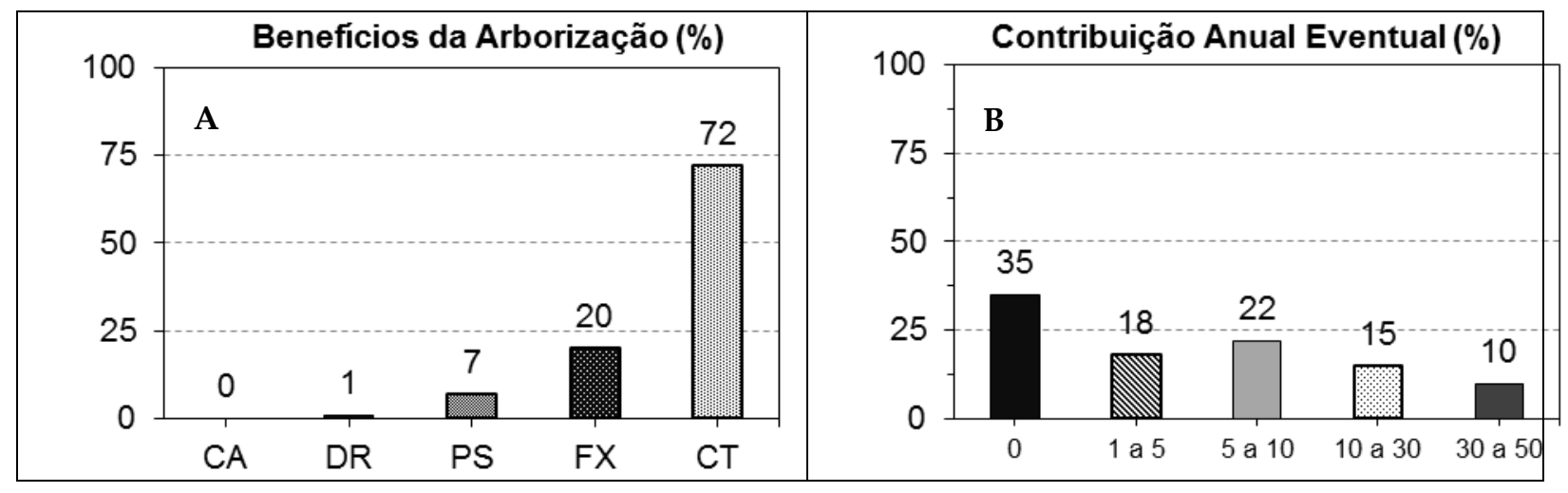

Figura 4 - Benefícios da arborização apontados pelos participantes da pesquisa (A) CA: conforto acústico; DR: drenagem; PS: paisagismo; FX: fixação de gases do efeito estufa; CT: conforto térmico; e contribuição anual eventual em reais (B), onde: 0: não contribuiria; 1 a 5: contribuiria de um a cinco reais por ano; 5 a 10: cinco a dez reais por ano; 10 a 30: dez a trinta reais por ano e 30 a 50: contribuiria com trinta a cinquenta reais por ano.

Quando perguntados sobre onde deveriam ser aplicados os investimentos na criação e manutenção dos espaços verdes urbanos, $33 \%$ dos entrevistados disseram que o plantio de novas árvores deveria ser priorizado (Figura $5 \mathrm{~A}$ ).

O segundo item, que fora atribuído como sendo aquele de maior relevância pela população, foi a irrigação de plantas e mudas já existentes na cidade, com $18 \%$, superior até a itens como a adubação, poda e campanhas contra o vandalismo, sendo eles $16 \%, 17 \%$ e $16 \%$, respectivamente. Este resultado faz sentido quando se pensa nas altas temperaturas, que são características da cidade. Por outro lado, pode indicar, também, o reconhecimento dos citadinos ao descaso com o que administrações passadas trataram o assunto e que quando faziam novas intervenções como o plantio de novas árvores, as mesmas eram abandonadas a própria sorte, dependendo da chuva para sobreviver, não havendo, no caso, planos ou cronogramas para nutrição, poda e hidratação destas.

Quando questionados sobre o Plano Diretor de Arborização Urbana (PDAU), mais de 80\% dos participantes afirmaram desconhecer e cerca de $20 \%$ participaram da sua elaboração ou ouviram falar deste plano. Sobre terem participado anteriormente de alguma pesquisa sobre arborização ou outras questão ambiental, apenas 9\% disseram sim, contra 91\% não, demonstrando que ainda são poucos os trabalhos desenvolvidos sobre estes temas na capital amazonense.

Dentre as espécies citadas pelos participantes da pesquisa, muitas estão previstas no PDAU, indicando que as espécies que serão utilizadas agradarão a população, como o pau pretinho e ipê, que apareceram com $16 \%$ cada, sendo estas as espécies mais lembradas, seguidas por mangueira ( $8 \%$ ) e frutíferas em geral (8\%) (Figura 5B). Outras espécies que já foram empregadas na arborização em Manaus no passado também foram lembradas, como oiti, flamboyant, benjamim e castanholeira. Apesar de algumas pessoas não apontarem uma espécie específica, $5 \%$ dos entrevistados se manifestaram a favor da utilização de espécies nativas da região amazônica. 


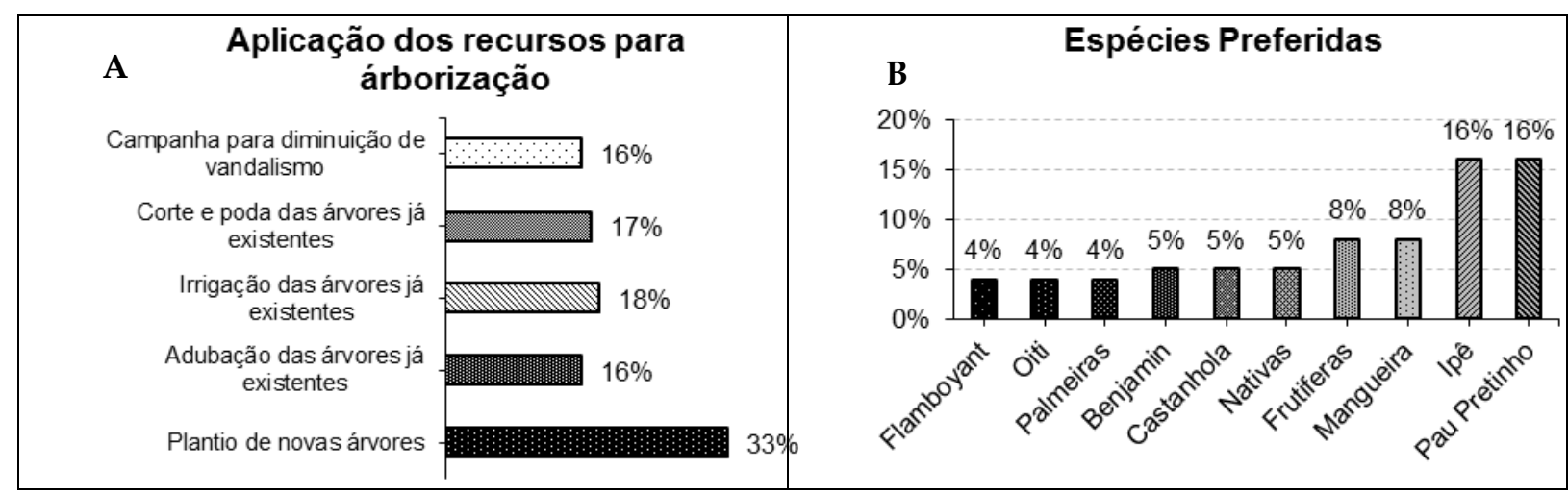

Figura 5 - Como deveriam ser aplicados os recursos (A) e as espécies preferidas pelos participantes da pesquisa para a arborização na cidade de Manaus.

Com relação às desvantagens eventuais da arborização urbana, foram consideradas como de maior preocupação o risco de tombamento, totalizando $25 \%$ dos resultados. Seguido de perto pelo risco de interferência na rede elétrica com $24 \%$ e rachaduras nas calçadas e obstrução do transito de pedestres com $21 \%$ (Figura 16). Vale salientar que todas estas desvantagens apontadas pelos participantes da pesquisa podem ser reduzidas e ou até eliminadas quando existe um planejamento prévio na implantação e manutenção dessas novas árvores.

Para $14 \%$ dos participantes, a arborização não apresenta qualquer tipo de desvantagens, enquanto para $13 \%$ afetam a iluminação pública e para apenas $3 \%$, a sujeira promovida pelo excesso de galhos, folhas e dejetos dos pássaros causam algum incomodo.

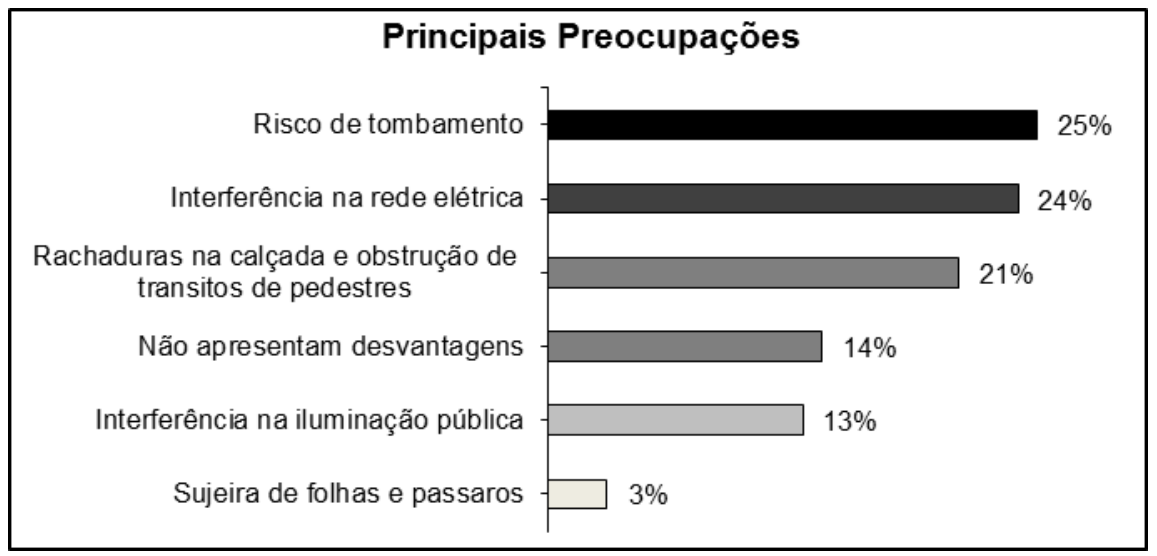

Figura 6 - Principais preocupações que a arborização pode trazer aos moradores.

Quando questionados sobre os valores destinados a arborização, conforme a lei orçamentaria de 2013, para a cidade de Manaus, $47 \%$ dos participantes julgaram como "muito ruim", seguido por "ruim", com 24\% (Figura 7), enquanto "bom" e "muito bom" totalizaram apenas $8 \%$, quando somados.

Essa insatisfação demonstrada na pesquisa esta alinhada com o resultado apresentado pelo IBGE (2010) que aponta Manaus como uma das piores capitais do país no quesito arborização urbana dos espaços públicos. Muito atrás da primeira colocada, Campo Grande, com 96,4\% de espaços verdes, e megalópoles como São Paulo, que com 75,4\%, aparece na oitava posição. 


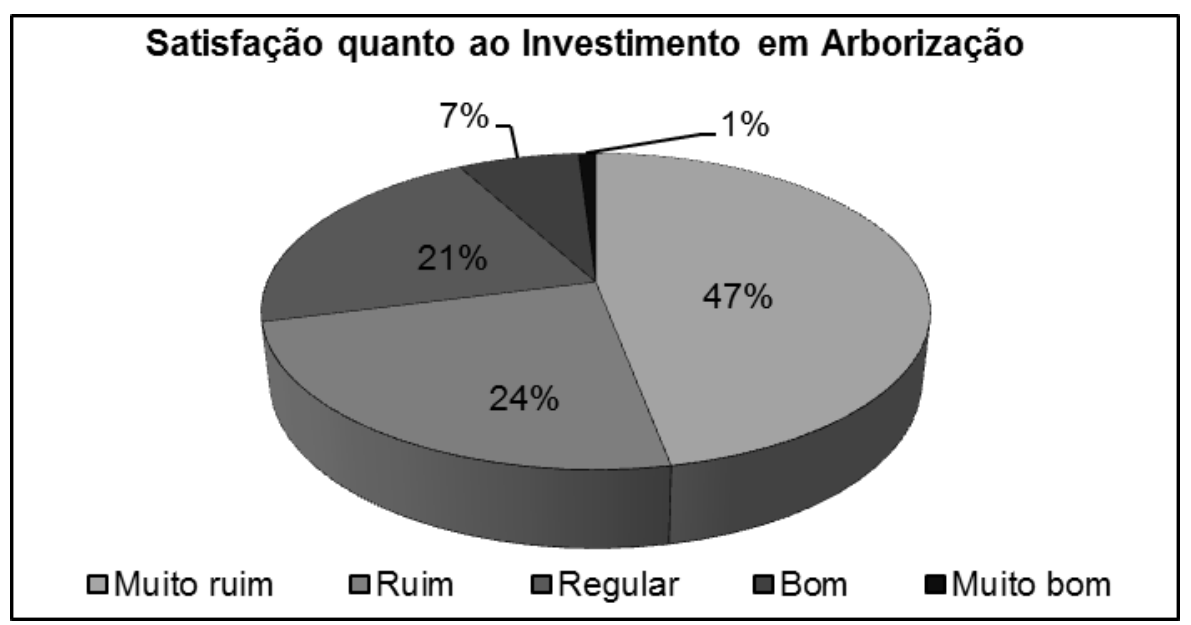

Figura 7 - Classificação da qualidade do investimento em arborização segundo os entrevistados.

Quando confrontadas as Leis Orçamentarias Anuais (LOA) com o percentual destinado as secretarias de meio ambiente destas capitais, que geralmente são as secretarias competentes para a implantação e manutenção de espaços verdes nas cidades, é possível notar algumas diferenças que podem auxiliar no entendimento com relação às posições ocupadas por estas nos resultados apresentados pelo IBGE (2010).

Na cidade de Campo Grande, foram destinados cerca de 2,42\% do PIB municipal para a Secretaria Municipal de Meio Ambiente e Desenvolvimento Urbano (SEMADUR). Este valor corresponde a mais de 43 milhões de reais (CAMPO GRANDE, 2012). Já na cidade de São Paulo, o valor destinado a Secretaria Municipal do Verde e do Meio Ambiente (SVMA), foi muito superior, cerca de 229,5 milhões de reais (SÃO PAULO, 2012). No entanto, este valor representa apenas $0,55 \%$ do PIB paulistano.

Apesar de não diferir muito de São Paulo, quanto ao percentual do PIB destinado a Secretaria Municipal de Meio Ambiente e Sustentabilidade (SEMMAS), com 0,49\% do PIB, a capital amazonense aparece como a que menos investe proporcionalmente a arrecadação municipal dentre as citadas sendo 17 milhões de reais (MANAUS, 2012). Isto pode explicar, em parte, o porquê de sua má avaliação no levantamento do IBGE em 2010 (Figura 8).

Outro ponto que contribui para explicar estes resultados é quando se distribui estes valores pela extensão territorial dos municípios. A cidade de São Paulo, nesse item, apresenta uma proporcionalidade de mais de $\mathrm{R} \$ 150.000,00 / \mathrm{km}^{2}$, sendo, assim, a que mais investe, nessa modalidade. No entanto, é a cidade que apresenta menor extensão territorial, apenas $1.521 \mathrm{~km}^{2}$, enquanto Campo Grande com $8.092 \mathrm{~km}^{2}$ e Manaus com $11.401 \mathrm{~km}^{2}$ investem $\mathrm{R} \$ 5.325,25 / \mathrm{km}^{2}$ e $\mathrm{R} \$ 1.503,36 / \mathrm{km}^{2}$, respectivamente (IBGE, 2013).

No caso da cidade Norte-Brasileira, sua extensão territorial é quase 10 vezes maior que a capital paulista, tornando, assim, o planejamento e a implantação de novas áreas verdes, um desafio maior.

Quando os valores repassados as secretarias de meio ambiente dos municípios são distribuídos em função do número de habitantes, novamente, Manaus, apresenta os menores números, com apenas $\mathrm{R} \$ 8,65$ investidos em arborização por habitante que, segundo o IBGE (2013), possui população estimada de 1.982.177. O segundo menor valor é apresentado por São Paulo, que apesar do grande volume de recurso aplicado no item anterior, é o município mais populoso do Brasil, com 11.253.503, assim, o valor do investimento é diluído, chegando a $\mathrm{R} \$ 20,40$. Já Campo Grande, com população de 786.797 habitantes (IBGE, 2013), apresenta o maior resultado, sendo investidos $\mathrm{R} \$ 54,78$ por habitante (tabela 3). 
Tabela 3. Comparação de investimentos entre as capitais Campo Grande, São Paulo e Manaus em função do percentual do PIB municipal (PIB\%), reais por quilômetros quadrados $(\mathrm{R} \$ / \mathrm{km} 2)$ e reais por habitante $(\mathrm{R} \$ / \mathrm{Hab}$.).

\begin{tabular}{cccc}
\hline \multirow{2}{*}{ Tipo de Investimento } & \multicolumn{3}{c}{ Investimentos por Capital } \\
\cline { 2 - 4 } & Campo Grande & São Paulo & Manaus \\
\hline PIB $(\%)$ & 2,42 & 0,55 & 0,49 \\
$\mathrm{R} \$\left(\mathrm{~km}^{2}\right.$ & $5.325,25$ & $150.899,47$ & $1.503,36$ \\
$\mathrm{R} \$ / \mathrm{Hab}$. & 54,78 & 20,40 & 8,65 \\
\hline
\end{tabular}

Os resultados relativos aos valores investido em arborização na cidade de Manaus apresentaramse, sistematicamente, menores que nas outras capitais avaliadas, o que poderia explicar sua colocação no ranking do IBGE. No entanto, alguns valores como a relação de investimento por habitantes e o percentual do PIB municipal destinado à arborização não foram tão inferior a São Paulo, que ocupa a $8^{a}$ posição no referido ranking, enquanto a Capital Amazonense é a antepenúltima colocada, na 25a posição.

Uma possibilidade seria o quanto dos recursos destinados a SEMMAS são aplicados, efetivamente, na implantação da arborização e gestão das áreas verdes da cidade, pois, sabe-se que o orçamento destinado a cada autarquia deve ser rateado para custear seus materiais de expediente, seus programas, projetos, funcionários e as atividades que estas executam.

No caso da SEMMAS, do valor de R $\$ 17.140 .000,00$ para o seu funcionamento, 2,8\% deste montante é destinado ao Programa Manaus Mais Verde (PMMV), que está vinculado diretamente com a arborização, através de ações de educação ambiental, proteção e implantação de áreas verdes na cidade.

Apesar dos esforços positivos neste sentido, quando consideramos apenas o valor investido efetivamente para a implementação do paisagismo e da arborização urbana, este valor é de apenas $\mathrm{R} \$ 165.000,00$, o que representa menos de 1\% do orçamento anual da secretaria. Quando confrontado com o orçamento municipal, esse valor torna-se menos representativo ainda, sendo de apenas $0,0049 \%$ do total.

Se o investimento relativo não difere demasiadamente da cidade de São Paulo, como observado anteriormente, o resultado da avaliação durante as entrevistas nesta pesquisa e no ranking do IBGE podem estar associados a questões mais amplas ou profundas, passando pelo âmbito da gestão das instituições e de seus programas quanto ao uso dos recursos de que dispõem e na forma que os aplicam, o que poderia explicar, assim, os resultados obtidos nesta pesquisa.

\section{Conclusão}

Durante este estudo, foi possível verificar que há insatisfação da população com a arborização urbana da cidade de Manaus, sendo as zonas norte e leste as com piores avaliações. Foi possível, também, identificar que a maior preocupação dos manauenses quanto à arborização urbana é o risco de tombamento das árvores. Apesar disso, mais da metade dos munícipes que responderam o questionário reconheceram a importância da arborização urbana para a cidade de Manaus, principalmente, para o auxilio ao conforto térmico e o sombreamento.

Foi possível identificar que houve uma fraca participação popular em questões relacionadas à arborização e meio ambiente na cidade e, apesar de considerado insuficiente os investimentos, mais de um terço dos entrevistados não estariam dispostos a contribuir com qualquer valor para melhorar e ou ampliar os espaços verdes da cidade de Manaus.

Com relação aos investimentos para a arborização feito pelo governo municipal manauense, quando comparado a outros municípios, ficou claro que estes aparentam ser insuficientes ou pouco expressivo, o que foi corroborado por pesquisas referente a qualidade da arborização de grandes cidades brasileira e principalmente pela insatisfação popular, observada neste estudo. 


\section{Referências}

CAMPO GRANDE. Lei no 5.118, de 26 de Dezembro: Orçamento 2013. Diário Oficial de Campo Grande. Ano XV, Ed 3.670. Campo Grande, MS. 2012. 79p.

CASTELLS, M. A galáxia da internet: reflexões sobre internet, negócios e sociedade. Fundação Calouste Gulbenkian. Lisboa, Portugal. 2004. 243p.

CEMIG. Manual de arborização. Companhia Energética de Minas Gerais / Fundação Biodiversitas. Belo Horizonte, MG. 2011. 112p.

COSTA, J. R.; SOARES, J. E. C.; TÁPIA-CORAL, S.; MOTA, A. M. A percepção ambiental do corpo docente de uma escola pública rural em Manaus (Amazonas). Revista Brasileira de Educação Ambiental. v.7. Rio Grande, RS. 2012. p.63-67.

IBGE. Acesso à internet e posse de telefone móvel celular para uso pessoal 2005. In: PNAD. Rio de Janeiro, RJ. 2006. 33p.

IBGE. Características urbanísticas do entorno dos municípios. In: Censo demográfico. Rio de Janeiro, RJ. 2010. p.1-175.

IBGE. Cidades. 2013. Disponível em: http://cidades.ibge.gov.br/xtras/home.php Acesso em: 22/11/2013.

LÜDKE, M. e ANDRÉ, M. Pesquisa em educação: abordagens qualitativas. EPU. São Paulo, SP. 1986. Disponível em: <http://pt.scribd.com/doc/67389090/LUDKE-Menga-Pesquisa-em-educacaoabordagens-qualitativas-Sao-Paulo-EPU-1986>. Acesso em: 24/11/2013.

MALAVASI, U. C. e MALAVASI, M. M. Avaliação da arborização urbana pelos residentes: estudo de caso em Mal. Cândido Rondon, Paraná. Ciência Florestal, v.11, n.1. Santa Maria, RS. 2001. p189-193.

MALHOTRA, N. 2006. Pesquisa de marketing: uma orientação aplicada. Bookman, $4^{\mathrm{a}}$ Ed. Porto Alegre, RS. 720p.

MANAUS. Lei no 1.709, DE 04 DE JANEIRO DE 2013: Lei Orçamentaria Anual - LOA 2013. Diário Oficial do Município de Manaus. Ano XIV, Ed. 3.081. Manaus, AM. 2012. 142p.

MASCARÓ, J. J. Análise da opinião da população sobre a arborização urbana em bairros de diferentes classes sociais. In: Revista da Sociedade Brasileira de Arborização Urbana - REVSBAU. v.7, n.4. Piracicaba, SP. 2012. p69-76.

MAZOYER, M. e ROUDART, L. História das agriculturas no mundo: do neolítico à crise contemporânea. Ed. UNESP. São Paulo, SP. 2010. 568p.

MILANO, M.S. Avaliação e análise da arborização de ruas de Curitiba-PR. Dissertação (Mestrado em Engenharia Florestal), Setor de Ciências Agrárias, Universidade Federal do Paraná. Curitiba, PR. 1984. 130p.

NERY, M. C. De Volta ao País do Futuro: Crise Europeia, Projeções e a Nova Classe Média. FGV/CPS. Rio de Janeiro, RJ. 2012. 126p.

OKAMOTO, J. Percepção Ambiental e Comportamento. In: Plêiade, São Paulo, SP. 1996. 200p.

OLIVEIRA, R.F. de. Urbis Arboreto: o espaço primitivo interpretado. In: Anais do Seminário de Arborização Urbana no Rio De Janeiro. UFRJ. Rio de Janeiro, RJ. 1996. p33-44.

VILLAR, L. M. et al. A percepção ambiental entre os habitantes da região noroeste do Estado do Rio de Janeiro. In: Esc. Ana Nery Rev. Enfermagem. v.12, n.2. Rio de Janeiro, RJ. 2008. p285-290.

PARASURAMAN, A. Marketing research. Addison Wesley Publishing Company, 2.ed. Boston, MA, USA. 1991. 638p. 
RIBEIRO, L. C. de Q. e RIBEIRO, M. G. IBEU: Índice de Bem-estar Urbano. Observatório das Metrópoles (INCT). Letra Capital. 1.ed. Rio de Janeiro, RJ. 2013. 264p.

SÃO PAULO. Lei no 15.680, de 27 de Dezembro: LOA 2013. Secretaria do Governo Municipal. São Paulo, SP. 2012. 12p.

SHNEIDERMAN, B. Designing the user interface; strategies for effective human-computer. interactive. 3. ed. Addison Wesley. Nova York, NY. 1998. 639p.

SOUZA, A. P. Diga-me via Internet: site oferece pesquisas de campo online. Meio \& Mensagem. ano 22, u. 920. São Paulo, SP. 2000. 36p.

ROPPA, C.; FALKENBERG, J. R.; STANGERLIN, D. M.; BRUN, F. G. K.; BRUN, E. J.; LONGHI, S. J. Diagnóstico da percepção dos moradores sobre a arborização urbana na vila estação colônia bairro Camobi, Santa Maria - RS. Revista da Sociedade Brasileira de Arborização Urbana, v.2, n.2. Piracicaba, SP. 2007. p.11-30.

TORRES, A. L. G. Ambiente urbano: o viver no conjunto habitacional Nova Cidade, Manaus/AM. Dissertação (Mestrado em Ciências do Ambiente - PPGCASA) - Universidade Federal do Amazonas - UFAM. Manaus, AM. 2009. 114p.

VIEIRA, H. C.; CASTRO, A. E. e SCHUCH JÚNIOR, V. F. O uso de questionários via e-mail em pesquisas acadêmicas sob a ótica dos respondentes. In: XIII Seminário em Administração SEMEAD. Universidade de São Paulo. São Paulo, SP. 2010. 13p. 